\title{
A análise dos dados da História Oral: fundamentos para uma Psicologia Crítica ${ }^{1}$
}

\author{
Data analysis of the Oral History: Foundations for a Critical \\ Psychology
}

\section{Mara Salgado*}

Universidade Federal de Santa Catarina - UFSC, Florianópolis, Santa Catarina, Brasil

\section{Kety Valéria Simões Franciscatti**}

Universidade Federal de São João Del-Rei - UFSJ, São João Del Rei, Minas Gerais, Brasil

\section{RESUMO}

Este artigo parte da pesquisa "Narrativas de artesãos: documentos da memória mineira" e traz como foco a reflexão sobre os limites e as potencialidades do método de pesquisa História Oral, com orientação das contribuições dos autores da Teoria Crítica da Sociedade, mais especificamente, Adorno, Horkheimer e Benjamin. A História Oral como método de pesquisa permite uma maneira de fazer ciência que reclame por meios de superação da conformada crise que assola o campo científico, por valorizar a razão como saber intelectual e sensível, pois é necessário ao pesquisador e ao entrevistado acessarem a subjetividade tanto para narrar, interpretar e se apropriarem daquilo que foi narrado, ouvido e sentido no campo da pesquisa. Nesse sentido, o trabalho retoma as considerações de Adorno (1959/1986; 1931/1991) acerca da formação cultural e da Fantasia Exata, como forma de interpretação dos dados obtidos com os métodos empíricos.

Palavras-Chave: formação cultural, memória, subjetividade, artesanato.

\begin{abstract}
This article starts from the research "Narratives of artisans: documents from memory of Minas Gerais" (Brazil), and its reflection focuses on the limits and the potential of Oral History research method, guided by contributions of the authors of Critical Theory of Society, more specifically, Adorno, Horkheimer and Benjamin. The Oral History as a research method allows a manner of doing science that claims by means of overcoming the conformed crisis that damages the scientific field, valorizing the reason as an intellectual and sensitive knowing, because it is necessary to researcher and to interviewee to access the subjectivity to narrate, interpret and to appropriate what was narrated, heard and felt in the research field. In this way, the paper takes into consideration Adorno's regards (1959/1986; 1931/1991) about cultural formation and the Exact Fantasy how to interpret the data obtained using empirical methods.
\end{abstract}

Keywords: cultural formation, memory, subjectivity, handicraft. 


\section{Introdução}

Este artigo apresenta estudos realizados com o trabalho de Extensão em interface com a pesquisa Narrativas de artesãos: documentos da memória mineira ${ }^{2}$, desenvolvida com financiamento da FAPEMIG na Universidade Federal de São J oão del-Rei, e investigou os aspectos da formação cultural presentes no ofício do artesão possíveis de serem observados nas narrativas dos próprios artesãos da região do Campo das Vertentes/MG. O trabalho apóia-se, em seus aspectos teóricometodológicos, nos estudos dos autores da Teoria Crítica da Sociedade, mais especificamente nas contribuições de Adorno, Horkheimer e Benjamin e nos pressupostos do método da História Oral. Para tal, foram selecionados, nas cidades com produção artesanal significativa na região do Campo das Vertentes que circundam a cidade de São J oão del-Rei, artesãos que se dispuseram a narrar suas histórias. Como instrumento de coleta dos dados, em especial as narrativas dos artesãos, utilizou-se câmera filmadora e fotográfica, além dos diários de campo da equipe de trabalho. Foram realizados os devidos procedimentos de pesquisa, como a apresentação e a aceitação, por parte dos entrevistados, do termo de consentimento livre e esclarecido e autorização para o uso de imagem.

A escolha pela contribuição do método da História Oral se justificou pelo acúmulo de dados e reflexões realizadas e sistematizadas pelas autoras deste trabalho, acerca do processo de criação e produção artesanal das cidades do Campo das Vertentes a partir da análise documental da Corporação de Artesãos de Tiradentes - CAT e da análise das primeiras entrevistas realizadas com os artesãos vinculados à CAT. Dessa maneira, a proposição do desdobramento de estudos antecessores parte do entendimento de que é o objeto da pesquisa que deve delimitar o método e, não o contrário. Destaca-se a importância do prévio aprofundamento teórico a respeito do objeto de pesquisa eleito, como condição da boa utilização do método da História Oral, na apreensão e produção de um conhecimento crítico.

O trabalho contou com a produção de um filme documentário, intitulado Narrativas de artesãos - o tal do filme ${ }^{3}$, de noventa minutos de duração, realizado a partir da edição das entrevistas com dezenove artesãos de algumas cidades da Região das Vertentes/MG, com produção artesanal significativa, a saber: São João Del Rei, Tiradentes, Santa Cruz de Minas, Prados, Vitoriano Veloso (Prados), Resende Costa, Conceição da Barra de Minas e Coronel Xavier Chaves.

Os artesãos entrevistados trabalham principalmente com escultura em madeira, escultura em lata, pintura, tear, boneca de pano, papel 
machê, costura, bordado, colagem de materiais naturais e modelagem em cerâmica.

A seleção dos artesãos numa região com vasta produção artesanal pode ser apontada como um grande desafio do projeto. Atentos a tal dificuldade, para que a seleção dos artesãos correspondesse à produção regional, foram estabelecidos critérios a partir de características do produto artesanal que apresentassem aproximações e distanciamentos com a arte e com o artesanato, a saber: a forma estilística, a unicidade da peça, a fabricação de objetos que seguem certos padrões característicos da produção regional, assim como, características quanto à matéria-prima utilizada e a dedicação ao ofício artesanal como principal fonte de sobrevivência. Buscou-se também, a seleção de artesãos que possuíssem certo reconhecimento junto às suas comunidades, e que trabalhassem tanto associados, como não associados em cooperativas ou associações de artesãos. Além, do critério de disposição do artesão em participar da pesquisa e do filme produzido. Destaca-se que a edição do filme se pautou nos resultados da pesquisa e foi elaborada por meio das falas dos próprios artesãos, seguindo o critério primeiro de que o filme se configurasse como parte da devolutiva da pesquisa aos artesãos. Entende-se que a estratégia do registro fílmico como parte da pesquisa, merece estudos cuidadosos acerca do apelo técnico que representa, entretanto contém a possibilidade de apresentar aos entrevistados a imagem e a fala, elementos que contribuem com a percepção do corpo e suas ações. Para um ofício que depende do trabalho das mãos em comunicação com os sentidos para a objetivação de seu produto, parece relevante a sinalização do corpo nas reflexões propostas. Com base em Türcke (2010), nos tempos modernos os sentidos encontram-se obstruídos e seus restos guiados por uma sociedade excitada por choques audiovisuais, desse modo, talvez o campo científico não possa abrir mão destes recursos na tentativa de alcançar os sujeitos. Vale dizer, que a imagem por si só não possui a chave para recuperar a sensibilidade obstruída, pelo contrário, cede a esta condição. Entretanto, é capaz de registar momentos de continuidade e ruptura por meio das contradições entre o corpo, a fala e o comportamento representados na imagem. Contradições fugidias no automatismo do cotidiano, que ao serem confrontadas com os discursos que surgem do entrelaçamento com outros atores, podem suscitar o reconhecimento de que algo da ilusão sobre a vida e sobre si mesmo fora abalado, de que algo escapa da disposição corporal e do discurso, revelando o ator e o personagem de cada um, ainda que acidentalmente.

Tais tensões teórico-metodológicas que subsidiam a busca pelo salto qualitativo na esfera do conhecimento nortearam, também, o trabalho de edição das filmagens, conservando no filme documentário 
rastros do conhecimento acadêmico, o que possibilitou o fomento de espaços de discussão com os artesãos e suas comunidades, ainda que timidamente. Desse modo, o desenvolvimento de um trabalho empírico, atento às suas implicações, promove um importante diálogo entre comunidade acadêmica e o entorno da universidade, contribuindo para a divulgação do conhecimento produzido em ambas as esferas. Sendo assim, a pesquisa traz contribuições importantes tanto na formação dos pesquisadores, quanto no contato com a comunidade, por ter como base de reflexão a necessidade de entendimento da realidade.

Contudo, se é necessário pensar estratégias para o entendimento da realidade é necessário, também, reconhecer a denúncia do estado de regressão intelectual em que a cultura se encontra, e que a vida não tem encontrado fruição na realidade. Por um lado, o registro das entrevistas realizadas pela filmadora traz possibilidades como: a contribuição com um acervo importante da memória de uma região, a possibilidade de uma devolutiva aos entrevistados e a comunidade numa linguagem não acadêmica, além de uma maior difusão da pesquisa/intervenção. Por outro lado, há de se considerar que o uso de um instrumento de captação de imagens interfere substancialmente no conteúdo discursivo dos entrevistados. Ainda que, este limite tenha sido considerado e abrandado por um roteiro de entrevistas proveniente do aprofundado estudo sobre o objeto, e principalmente, um roteiro preocupado em não restringir o diálogo entre pesquisador e entrevistado, perde-se parte da já regredida autenticidade dos contatos entre as pessoas. O que se ressalta é a complexidade das teceduras no campo da pesquisa empírica.

Mas, como desenrolar os fios da trama emaranhada do indivíduo que nem se sabe indiferenciado de seu meio social? Como tecer os fios narrados na história de cada um com os desenhos que revelam os traços de todos? Tais indagações nortearam as reflexões deste trabalho e indicam a relevância da tensão dos limites e das potencialidades da experiência narrativa nos tempos atuais como fundamento para os caminhos vislumbrados pela História Oral, que revelem a dinâmica social, no privilégio da fala, das reminiscências e do diálogo.

\section{2 o método da História Oral: caminhos que defrontam a formação cultural}

Discorrer sobre método de pesquisa com base nos estudos da Teoria Crítica da Sociedade é apontar para a necessidade de confrontar o olhar pré-formado, para além do choque da consciência, em busca da crítica sobre a própria atuação no campo do conhecimento. Mais do que uma técnica a ser aplicada, o que os autores frankfurtianos 
propõem é a primazia da reflexão como salto qualitativo no método de pesquisa (Horkheimer \& Adorno, 1956/1973).

A História Oral como método de pesquisa permite uma maneira de fazer ciência que reclame por meios de superação da conformada crise que assola o campo científico, por valorizar a razão como saber intelectual e sensível, pois é necessário ao pesquisador e ao entrevistado acessarem a subjetividade tanto para narrar, interpretar e se apropriarem daquilo que foi narrado, ouvido, sentido no campo da pesquisa.

Pensa-se numa importante aproximação entre o potencial da História Oral e do objeto da Psicologia Social - a compreensão da subjetividade como elemento revelador da objetividade - como destacado por Portelli (2001), Bosi (1994), Khoury (2001) e enfatizado por Crochík (2008, p. 298) acerca das contribuições de Adorno, a saber: "(...) tipos de comportamentos expressados em sentimentos, pensamentos e tendências para as ações uniformes, padronizados".

Considerando a subjetividade como apropriação da objetividade social, parte-se de que a primeira potencialidade do método da História Oral reside em sua capacidade de vislumbrar a história individual concatenada com a história coletiva, ou seja, antes da interseção do particular e do universal está o aspecto revelador do conteúdo universal no âmago do conteúdo particular. É na relação dialógica que emerge do encontro entre pesquisador e entrevistado que reside a reivindicação do indivíduo (não realizado) por espaços nas configurações universais. Ao ser solicitado como narrador da própria história, o sujeito tem a possibilidade de se perceber como sujeito social e, nisto, revelar as condições das práticas sociais e as diversas formas de se perguntar qual lugar ocupa na realidade social. Para pensar o campo da História Oral, no que se refere à relação entre o pesquisador e o entrevistado e o enredo que surge desse encontro, é necessário alimentar-se das contribuições de Theodor Adorno (1959/1996) no texto Teoria da semicultura acerca da formação cultural. Como formação cultural os autores da Teoria Crítica da Sociedade entendem o processo da apropriação da cultura pelo indivíduo, nas palavras de Adorno (1959/1996) “(...) a cultura tomada pelo lado de sua apropriação subjetiva" (p. 399). Desse modo, pode-se dizer que formar-se é ter condições objetivas para reconhecer-se na experiência da vida social. Acontece que a história da humanidade vem se apresentando como a história da dominação dos homens sobre a natureza, sobre si mesmos e sobre os outros homens. Assim, as condições objetivas não só estão calcadas nessa dominação, como são mantidas por uma organização social que sobrevive à custa da obstrução da consciência humana, ou do que nos resta de humano, minando as possibilidades de reconhecimento da realidade por meio da falta de contato com os objetos, ou seja, 
minando as possibilidades da experiência. Adorno (1959/1996) nomeia tais condições de pseudoformação socializada, uma vez que a sociedade se estrutura na dominação, os homens impedidos de expressar-se de acordo com sua autoconsciência estão de antemão deformados, ou privados da experiência.

Com base em Benjamin (1933/1985) pode-se dizer que do empobrecimento da experiência - intensificada pelos meios de produção tecnológica - e, com isso, o avassalamento de informações que suprimem a comunicação viva das experiências, deriva um novo estado de barbárie ${ }^{4}$, no qual os homens, na tentativa de sobreviverem à cultura, se arrastam na ambigüidade da "desilusão radical com o século e da total fidelidade a esse século" (p. 116).

\section{Para este autor:}

Pobreza de experiência: não se deve imaginar que os homens aspirem a novas experiências. Não, eles aspiram a libertar-se de toda experiência, aspiram a um mundo em que possam ostentar tão pura e tão claramente sua pobreza externa e interna, que algo de decente possa resultar disso. Nem sempre eles são ignorantes ou inexperientes. Muitas vezes podemos afirmar o oposto: eles "devoram" tudo, a "cultura" e os "homens", e ficaram saciados e exaustos. "Vocês estão todos tão cansados - e tudo porque não concentraram todos os seus pensamentos num plano totalmente simples, mas absolutamente grandioso." Ao cansaço segue-se o sonho, e não é raro que o sonho compense a tristeza e o desânimo do dia, realizando a existência inteiramente simples e absolutamente grandiosa que não pode ser realizada durante o dia, por falta de forças. (Benjamin, 1933/1985, p. 118; aspas no original).

Ou nas palavras da tecedeira Dona Dadá:

A minha mãe já tecia. Da minha mãe são treze irmãos. Nós fomos criados na roça, meu pai não tinha salário, minha mãe criou nós tudo no tear. Ela fazia tudo na mão. Colcha de lã, linda! A mãe tecia até pano pra fazer terno pra casamento. Minha mãe fazia, ela tinha uma mão perfeita. Minha mãe trabalhava dia e noite. A família é muito grande, trabalhava na enxada em roça, e cuidava da casa, eu fui crescendo e ajudando também, né? $\mathrm{E}$ ela trabalhava direto no tear. Às vezes ela trabalhava de dia na roça e à noite ela fazia uma coberta no tear, de noite. Com luz de querosene naquela época, né, que não tinha... Lamparina que eles falavam. Na roça não tinha luz. E criou nós tudo no tear, nunca faltou nada pra nós. A gente não tinha assim, as coisas, grandiosas demais, 
mas graças a Deus o necessário nunca faltou. Minha mãe trabalhava muito, ela sofreu muito pra criar nós, ensinou nós tudo também a trabalhar, eu também passei pras minhas filhas, eu creio que elas vão passar pras minhas netas e vão indo de geração em geração, graças a Deus. (Dona Dadá, 56 anos. São J oão del-Rei, setembro de 2009.)

Adorno (1932/1991) em análise de pressupostos da primeira fase da fenomenologia ressalta a insuficiência do esforço em fundar a compreensão da filosofia no sentido atribuído pelo ser. Este autor apresenta a problemática entre ontologia e historicismo como categorias inseparáveis, transformadas em antíteses para a manutenção do mito da natureza e da história como bases imutáveis. A proposição do sentido como elemento capaz de descrever o fenômeno em si repõe a falsa idéia de que as condições de vida são estagnadas e que os sujeitos se norteiam pela autoreflexão a ponto de confrontarem a realidade com a experiência, com o contato com os objetos almejados, trajetos obstruídos por uma história calcada na expropriação da consciência e na exacerbação do medo.

Em O Mal Estar na Civilização, Freud (1929[30]/1974) indica como as fontes originais do sofrimento que interessam a quem quer que se arrisque no entendimento dos homens: o poder superior da natureza, a fragilidade dos corpos e a inadequação das regras que procuram ajustar os relacionamentos sociais. Esse autor nomeia o medo da morte quando se refere à fragilidade dos corpos como limitação corporal de tempo e espaço ligada e reforçada pelo princípio civilizador. Já que as regras de ajustamento social apóiamse na dominação, pode-se pensar que o que recai sobre os homens é a constante e repetitiva ameaça da morte, por meio da "sensação" de morte da pulsão. Tal caráter de ameaça repetitiva e reeditada transforma a pulsão, que na tentativa de se ligar a objetos de prazer, funciona como compulsão à repetição que na tentativa de conservar a vida pulsional conduz à busca incessante de objetos, sem ligar-se a nenhum objeto. Enquanto a cultura reeditar a ameaça de morte, e o auto-investimento da libido for ativado por mecanismos de defesa, os homens estarão impedidos de autoreflexão, provinda do contato com a realidade e, nisso, cada vez mais comprometidos em suas constituições psíquicas, mais afastados daquilo que traria a vida ao cotidiano: as reminiscências, a experiência para ser lembrada, contada e elaborada.

Neste intento, vale a atenção para a concepção da História Oral como método de pesquisa que deve se apropriar de contribuições de outras disciplinas no privilégio da teoria como sustentáculo do conhecimento produzido historicamente, inclusive pelas fontes orais (Amado \& Ferreira, 2005). O método que alcança espaço nos 
cenários da pesquisa necessita de elaboração e consistência teórica para alcançar seus objetivos de reivindicação da auto-reflexão por parte tanto do entrevistado quanto do pesquisador.

Em fecunda discussão sobre a teoria e a práxis Adorno (1969/1995) também elege a auto-reflexão, o pensamento, como potencialidades opositoras aos traços que aprisionam a práxis, esta entendida como domínio da natureza. Nas palavras do autor, "se a práxis autárquica possui desde sempre traços maníacos e coercitivos, a auto-reflexão significa - em contraste com estes - interromper a ação cega que tem seus fins fora de si, e o abandono da ingenuidade, como passagem para o humano" (Adorno, 1969/1995, p. 206). Desse modo, o autor ressalta a questão da perda da experiência na relação entre teoria e práxis, questão que se entrelaça com o conhecimento, com o modo como teoria e práxis são separadas e desfiguradas, com prejuízo para o pensamento. A teoria é tomada como impotente e a práxis como arbitrária.

Há de se pensar sobre as consequências de pessoas constituídas pela ideologia que nega que "pensar é um agir", ao analisar seus diálogos como latências factuais da realidade. Ao que parece, ela, a realidade, torna-se obscura e mítica não por ser incógnita, mas por não deixar dúvidas das ameaças que representa.

\section{Memória e consciência: elementos em choque no mito da realidade}

Em análise de texto freudiano sobre a correlação entre memória e consciência Benjamin (1939/1989) destaca que o aparelho psíquico sofre um choque traumático ao se proteger das excitações externas impedindo que a consciência sofra seus impactos excessivos. O sistema percepção-consciência ativa um filtro capaz de armazenar os traços mnêmicos a partir das percepções do mundo externo, ou seja, tal sistema garante à consciência a memória subjetiva da realidade. Porém, quando o aparelho psíquico se organiza para a constante defesa contra os choques traumáticos, mobiliza a consciência para um estado de alerta que diminui o armazenamento de traços mnêmicos, caracterizando o empobrecimento da memória (Rouanet, 1990, p. 65).

Para Rouanet (1990), essa leitura de Benjamim sobre o choque da consciência se constitui como a principal crítica cultural deste autor:

Essa leitura da teoria freudiana do choque constitui a chave da crítica cultural, de Benjamin. Para ele, com efeito, o mundo moderno se caracteriza pela intensificação, levada ao paroxismo, das situações de choque, em todos os domínios. 
Na esfera econômica, o capitalismo institucionalizou a produção em série e o tipo de trabalho que lhe corresponde, que é a cadeia de montagem. Ora, essa forma de trabalho implica a adaptação do ritmo do operário ao ritmo da máquina, e esse ritmo consta de movimentos autárquicos, que na perspectiva do operário individual não têm entre si qualquer relação teleológica, com vistas à elaboração, fase por fase, do produto final, mas constituem agregados mecânicos de momentos sempre iguais, sem nenhum vínculo orgânico com os momentos anteriores e posteriores, e muito menos com o conjunto do processo produtivo. O operário tem que reagir, como um autômato, aos estímulos da máquina, que Ihe impõe uma resposta reflexa, e Ihe transmite uma espécie de choque elétrico, que a cada minuto se repete, para desencadear um novo movimento muscular, em tudo idêntico ao anterior. (Rouanet, 1990, p. 66.)

No caso dos artesãos, percebe-se que estes também não têm conseguido escapar da administração do ritmo despersonalizado da máquina. Com o trabalho artesanal subvertido aos valores da indústria: a alta produtividade e o lucro resta, a seu ofício a reação ao choque na padronização de seus produtos.

Espaços que poderiam guardar brechas para a experiência se perdem numa realidade encoberta pela mecanização do homem, que, movido pelo medo e por mecanismos psíquicos de defesa contra as condições anacrônicas de sobrevivência, não se reconhece como dono de seu tempo, seu espaço, sua história. Base para pensar nos limites que permeiam o método da História Oral. Limites que não devem ser amenizados, mas refletidos, tensionados pela crítica capaz de reconhecer na práxis possibilidades de superação dos mitos que impedem as reminiscências e justificam a nãodiferenciação do indivíduo.

Atento às dimensões míticas presentes nas narrativas, Portelli (2005) diz da função do mito em "reconciliar os opostos" (p. 121), ou seja, não se trata de inventar uma história para narrar, mas encontrar na cultura significados que suportem tais mitos, que justifiquem e potencializem a existência individual no coletivo, a adesão às ilusões sociais. O autor ressalta ainda, que não se trata de retirar a legitimidade de quem fala, mas compreender que a memória que procede a narrativa é mediada socialmente, contudo não se restringe à memória social, a menos quando apresentada, ressaltada por meio do mito presente nas relações sociais.

Parece ser justamente na possibilidade de revelação das contradições que ainda emergem das narrativas que reside a força da História Oral como método de pesquisa e como método de intervenção social, por mais que tais contradições sejam limadas 
pela coesão social e omitidas tanto nas ciências, quanto nas concepções do indivíduo sobre suas memórias.

Em reflexões acerca da teoria de Halbwachs, Bosi (1994) indica que mesmo as reminiscências, as lembranças que parecem expressões íntimas do sujeito, emergem desencadeadas pela situação presente e seus vínculos com as instituições sociais, são suscitadas pelos laços afetivos e pelas circunstâncias de quem lembra. A lembrança se organiza em imagens de acordo com a disposição psíquica e as percepções atuais da consciência, ao evocar os elementos que constituem o fato lembrado, a lembrança decodifica-se a partir das referências atuais, carregadas do sistema de representações que foi sendo construído durante a vida do indivíduo pela mediação social.

Fernando Rosa, artesão da cidade de Tiradentes, começa a contar a história de sua vida a partir de discussões concernentes ao artesanato regional e a influência da arte barroca mineira, que provavelmente não faziam parte de seu repertório na época, mas que Fernando reconhece, legitimamente, como parte constituinte de sua história de vida.

Eu comecei na verdade numa oficina de ourives, que toda a cidade trabalhava com jóias, fazia trabalho de prata, e nas casas tinham umas oficinas, meu tio tinha uma oficina dessas e eu fui trabalhar com ele, soldar, fazia colar e, a parte mais gostosa que tinha era quando ele mandava a gente criar: "Olha vocês fiquem à vontade eu quero que vocês criem alguma coisa" - aí a gente criava anel, era a maior delícia, a gente ganhava pra brincar e a gente criava mesmo, fazia umas coisas diferentes. Acabava encontrando os Ss barrocos. Tudo que a gente fazia parecia que já tinha uma alma desses Ss, assim, do barroco, né? (Fernando Rosa, artesão de Tiradentes, julho de 2009.)

Ou nas palavras de Adorno (1951/1993):

Não é a memória inseparável do amor, que pretende conservar o que passa? Não é cada impulso da fantasia engendrado pelo desejo, que, deslocando os elementos do existente, transcende-os sem traí-los? A mais simples das percepções não se forma no medo da coisa percebida ou no desejo desta última? Certamente o sentido objetivo dos conhecimentos desprendeu-se, com a objetivação do mundo, cada vez mais da base pulsional; certamente o conhecimento falha quando seu esforço objetivante permanece sob o encanto dos desejos. Mas, se as pulsões não são ao mesmo tempo suprassumidas [aufgehoben] no pensamento, que escapa desse encantamento, o conhecimento torna-se impossível, e o 
pensamento que mata o desejo, seu pai, se vê surpreendido pela vingança da estupidez. A memória é transformada num tabu como algo de imprevisível, não confiável, irracional. (pp. 106-107.)

Com esse entendimento, é necessário para transpor os limites da rigidez da ciência, reconhecer que a busca pela subjetividade e um de seus elementos representantes - a memória - deve partir da compreensão do material social que impregna e administra a formação cultural.

Recorremos as contribuições de Adorno (1931/1991) no texto La actualidad de la filosofia, quando o autor escreve acerca das relações entre a filosofia e a ciência. Crochík (2008), em rigoroso ensaio fundamentado na discussão proposta por Adorno, explica o termo Fantasia Exata, indicado por Adorno (1931/1991), para dizer da forma de interpretar os dados obtidos com os métodos empíricos, que representa a possibilidade de expressão do pensamento via imaginação e especulação - elementos formativos na produção do conhecimento afastados pela racionalidade positivista. Para Crochík (2008), tal formulação de Adorno quanto à análise do "material fornecido pelas ciências impede conceitos idealistas de serem fortalecidos" (p. 298) e, por estarem restritos aos objetos existentes, reconhecem a impossibilidade da apreensão total por meio de conceitos; esta - a totalidade - se expressa no particular via objetos cotidianos.

O que Adorno (1931/1991) ressalta é que toda pretensão da totalidade é ambivalente e se coloca como totalidade falseada, pois para ocultar o não cumprimento do todo, inibi o reconhecimento de que o universal se converteu em finalidade e não serve mais de meio viável para a realização do indivíduo. A pretensão da totalidade reafirma uma realidade que vem se apresentando como mito por suscitar os mecanismos de defesa capazes somente de anestesiar os homens diante de seus sofrimentos e, assim, livrá-los das possibilidades de reconhecer tais sofrimentos como conseqüências da adesão às exigências sociais.

Reconhecer o próprio sofrimento e identificar-se com o sofrimento alheio, associar o mal-estar mais às possibilidades de libertação traídas e/ou esquecidas do que à culpa, são brechas em que a formação do humano mostra-se no seu entremeio e indica possibilidades de sua realização como indivíduo. Portanto, reconhecendo e se comprometendo com sua dimensão política e em nome da realização do esclarecimento, é responsabilidade estrita da psicologia, no confronto com os aspectos objetivos e subjetivos e com o conhecimento produzido pelas outras ciências, pela filosofia e 
pela arte, desvelar os mecanismos psicológicos que permitem as pessoas aderirem à irracionalidade objetiva; desvelar como todos e cada um aceitam a dominação e a reproduzem como forma de ilusão e contra seus interesses mais racionais. (Franciscatti, 2007.)

Os autores chamam a atenção quanto ao papel das ciências em identificar nuances que contribuem para a regressão psíquica do eu. Lembrando que o empobrecimento psíquico é o fator responsável pela adesão da massa, ou melhor, do indivíduo-massa, em movimentos irracionais insistentes na história da humanidade.

Segundo Horkheimer e Adorno (1947/1985), o funcionamento dos mecanismos psíquicos presentes na adesão à ideologia fornece um roteiro pré-determinado de conteúdos firmados em prol da coesão social e agem contra os interesses mais racionais dos indivíduos, descritos como mentalidade do ticket, cujos elementos do cotidiano são categorizados e associados superficialmente como parte de uma mesma pauta. Nas palavras de Crochík (2008, p. 301), "antes dos mecanismos psíquicos entrarem em ação, os dados já são preparados socialmente para serem captados dessa forma".

Diante de perguntas superficiais (e também recorrentes), o entrevistado acessa num primeiro momento, os conteúdos informativos padronizados e fornecidos pelo meio social. Não é demais, então, ressaltar a importância do mergulho do pesquisador no tema que circunda o objeto delimitado, para que este - o pesquisador - não se dê por satisfeito diante das primeiras respostas do entrevistado. Satisfazer-se com a primeira resposta, ou com as respostas mais recorrentes, pode significar reduzir a análise das entrevistas à reprodução do discurso dominante.

O trecho a seguir destacado da entrevista de uma da artesã levanta algumas reflexões acerca de discursos produzidos sobre o ofício do artesão recorrentes em trabalhos acadêmicos empíricos realizados na região estudada e, mais ainda, em programas políticos de difusão do artesanato.

Minha avó, que eu nem lembro dela, ensinou pra minha mãe, minha mãe foi passando pra nós, a gente passa pros filhos. Vai ensinando os outros e lá vai pra frente, né? E é uma profissão, eu tava até conversando com a moça aqui, que é muito bom esse trabalho que vocês estão fazendo porque aqui nossa cidade tem muita dificuldade pra ter emprego, serviço principalmente pra dona de casa, né? I gual no meu caso, por exemplo, que eu não posso trabalhar fora, não tem jeito, então isso aqui você trabalha em casa, você trabalha a hora que você pode, né? (Dona Dadá, artesã tecedeira, 56 anos, São João del Rei, setembro de 2009.) 
A linha que desenrola a fala da artesã pertence ao novelo do todo. 0 todo fantasioso que finge que a divisão de trabalho, marca da forma atual de produção artesanal, não descaracterizou a experiência de transmissão do ofício de geração para geração. O todo dominante que impõe a presença das instituições de ensino, ou de ações políticas junto às comunidades, como se estratégias intragrupais dessem conta de transformar o que a sociedade nega aos indivíduos. $E$, certamente, um todo que formaliza ofícios e fazeres sem ao menos lembrar os direitos trabalhistas inexistentes nestes ofícios, como se o tempo de trabalho não tomasse todo o tempo de vida. As palavras da artesã contêm a categórica ordem do mundo do trabalho em que se "pode" trabalhar em todas as horas. Quando a razão que sustenta a dinâmica social é a razão tecnológica ou econômica, os homens com seus egos rebaixados ao passo mais curto, respondem automaticamente à pressão do todo sobre a parte. Os conteúdos discursivos dos homens não são abstraídos da realidade, são administrados por ela e representam a dialética do comportamento economicamente racional, em que aquilo que sobrevive nos homens contém a marca da mutilação que adere e resiste ao totalitarismo e se constitui como falsa consciência necessária, falsa por ser consciência administrada por interesses irracionais e, verdadeira por atender às satisfações instintivas das massas (Adorno, 1955/1986).

Desconsiderar o esforço necessário para a análise dos conteúdos discursivos, manifestados nas entrevistas da História Oral, seja por parte do entrevistado ou do entrevistador, é abrir mão do esclarecimento capaz de desvelar os representantes das forças coercitivas sociais. Cabe aos homens e às esferas de conhecimentos parcelares a crítica ao indivíduo, que não significa sua abolição, mas a reclamação de sua realização.

Tal esforço pode sim encontrar brechas para que escape alguma resistência aos comandos sociais, alguma reflexão, desde que a relação estabelecida seja de diálogo, contato, mesmo que breve, entre duas pessoas, com configurações específicas, que almejam tocar o mesmo objeto e, por isso descobrem caminhos sinceros a serem percorridos durante esse encontro.

Tais considerações devem constituir a problemática do diálogo proposto pela História Oral, e mais ainda, a análise desse diálogo, de modo a não rebaixar a finalidade de tal encontro: a possibilidade de reconhecimento de si no mundo, a denúncia do empobrecimento da memória, do embotamento da fantasia e da experiência humana.

Cabe às ciências primarem pela desobstrução das ilusões manifestas em torno de seu objeto. No caso da articulação da ciência psicológica com a História Oral: desvelar, tensionar os fios das narrativas que dão sentido à superação da subjetividade administrada, seja por meio dos gritos ou silêncios verbais e 
corporais dos sujeitos entrevistados, seja pela análise que dispensa a superficialidade, a preguiça e a falsa ingenuidade.

\section{Referências}

Adorno, T. W. (1931/1973a). La actualidad de la filosofía. In T. W. Adorno. Actualidad de la filosofía (Trad.: J. L. A. Tamayo) (pp. 73102). Barcelona: Ediciones Paidós.

Adorno, T. W. (1931/1973b). La idea de historia natural. In T. W. Adorno. Actualidad de la filosofía (Trad.: J. L. A. Tamayo) (pp. 103134). Barcelona: Ediciones Paidós.

Adorno, T. W. (1951/1993). Minima Moralia: reflexões a partir da vida danificada (Trad.: L. E. Bicca. 2.ed.). São Paulo: Ática.

Adorno, T. W. (1955/1986). Acerca de la relacion entre sociologia y psicologia. In H. Jense (Org). Teoria crítica del sujeto (pp. 36-83). Buenos Aires. Ed. Siglo XXI.

Adorno, T. W. (1959/1996). Teoria da semicultura (Trad.: N. Ramos-de-Oliveira, B. Pucci e C. B. M. de Abreu). Educação e Sociedade, Campinas: Papirus, n. 56, ano XVII, 388-411.

Adorno, T. W. (1968/1995). Educação contra a barbárie. In T. W. Adorno. Educação e emancipação. (Trad.: W. L. Maar, pp. 155-168). São Paulo: Editora Paz e Terra.

Adorno, T. W. (1969/1995). Notas marginais sobre teoria e práxis. In T. W. Adorno. Palavras e sinais: modelos críticos 2 (Trad.: M. H. Ruschel, pp. 202-229). Petrópolis: Vozes.

Amado, J., Ferreira \& M. M. (Orgs.). (2005). Usos \& abusos da história oral (7.ed.). Rio de Janeiro: Editora FGV.

Benjamin, W. (1933/1985). Experiência e pobreza. In W. Benjamin, Magia e técnica, arte e política: ensaios sobre literatura e história da cultura. (Trad: . S. P. Rouanet, pp. 114-119). Obras escolhidas vol. I. São Paulo: Editora Brasiliense.

Benjamin, W. (1939/1989). Sobre alguns temas em Baudelaire. In W. Benjamin, Charles Baudelaire um lírico no auge do capitalismo. (Trad:. H. A. Baptista, pp. 103-149). Obras escolhidas vol. III. São Paulo: Editora Brasiliense.

Bosi, E. (1994). Memória e Sociedade: lembranças de velhos (3.ed). São Paulo: Companhia das Letras.

Bosi, E. (2003). Memórias paulistanas. Estudos Avançados, v. 17, 198-210.

Crochík, J. L. T. W. (2008). Adorno e a psicologia social. Psicologia \& Sociedade, 20(2), 297-305.

Franciscatti, K. V. S. (2005). A maldição da individuação: reflexões sobre o entrelaçamento prazer-medo e a expressão literária. Tese de Doutorado em Psicologia Social, PUCSP. São Paulo, SP, Brasil. 
Franciscatti, K. V. S. (2007). Entre o gris e a irisação: limites da teoria e da práxis ante a ideologia afirmativa do existente. In C. Mayorga \& M. A. M. Prado (Orgs.), Psicologia Social: articulando saberes e fazeres (pp. 81-98). Belo Horizonte: Autêntica.

FREUD, S. (1929[30]/1974). O mal-estar na civilização. Edição Standard Brasileira das Obras Psicológicas Completas (V. XXI, 73171). Rio de Janeiro: Imago.

Gonçalves, R. C. \& Lisboa, T. K. (2007). Sobre o método da História Oral em sua modalidade trajetórias de vida. Revista Katályses 10 (número especial), 83-92.

Horkheimer, M. \& Adorno, T. W. (1947/1985). Dialética do esclarecimento: fragmentos filosóficos (Trad.: G. A. Almeida). Rio de Janeiro: Jorge Zahar.

Horkheimer, M. \& Adorno, T. W. (Orgs.). (1956/1973). Temas básicos da Sociologia (Trad. A. Cabral). São Paulo: Cultrix/USP.

Khoury, Y. (2001). Narrativas orais na investigação da história social. Projeto História, 22, 115-140.

Portelli, A. (2001). História Oral como gênero. Projeto História, 22, 9-36.

Portelli, A. (2005). O massacre de Civitella Val di Chiana (Toscana, 29 de junho de 1944): mito e política, luto e senso comum. In M. de Moraes Ferreira e J. Amado (Orgs.), Usos e abusos da História Oral (pp. 103-130). Rio de Janeiro: Editora FGV.

Salgado, M. \& Franciscatti, K. V. S. (2007). Arte, artesanato e trabalho: um estudo acerca dos limites e das potencialidades de resistência no fazer e criar artesanal. In Anais do $V$ Congresso de Produção Científica da Universidade Federal de São João Del-Rei XV Seminário de Iniciação Científica/SIC (CD-ROM, v.1). São João del-Rei: UFSJ .

Türcke, C. (2010) Sociedade excitada: filosofia da sensação. (Trad.: A. A. S. Zuin, F. A. Durão, F. C. Fontanella, M. Frungillo). Campinas, SP: Editora da Unicamp.

\section{Endereço para correspondência \\ Mara Salgado}

Universidade Federal de Santa Catarina - Centro de Ciências da Educação

Programa de Pós-Graduação em Educação - Doutorado

Bairro Trindade, CEP 88040-900, Florianópolis - SC, Brasil

Endereço eletrônico: marasalgado.ms@gmail.com

Kety Valéria Simões Franciscatti

Universidade Federal de São J oão Del-Rei (UFSJ)

Departamento de Psicologia

Praça Dom Helvécio, 74, Dom Bosco, CEP 36301-160, São João Del-rei - MG, Brasil

Endereço eletrônico: kety.franciscatti@gmail.com

Recebido em: 29/05/2012

Aceito para publicação em: 11/09/2013

Acompanhamento do processo editorial: Ana Maria Lopez Calvo de Feijoo 


\section{Notas}

* Graduada em Psicologia pela Universidade Federal de São J oão Del-Rei (UFSJ) MG. Mestre pelo Programa de Pós-Graduação em Educação da Universidade Federal de Santa Catarina (UFSC) - SC - Brasil.

** Mestre e doutora em Psicologia: Psicologia Social pela Pontifícia Universidade Católica de São Paulo (PUC/SP). Docente do Departamento de Psicologia (DPSIC), do Programa de Mestrado em Psicologia (PPGPSI) e pesquisadora do Laboratório de Pesquisa e Intervenção Psicossocial (LAPIP) da Universidade Federal de São J oão Del-Rei (UFSJ) .

1 Texto apresentado em versão preliminar no VIII Encontro Regional Sudeste de História Oral - Centros de Pesquisa em História Oral: trajetórias, abordagens e avaliações. FAFICH - UFMG, em outubro de 2009 sob o título: Potencialidades da História Oral: reminiscências da experiência narrativa?

2 Tal pesquisa apóia-se nas investigações realizadas na pesquisa Psicologia e Arte: reflexões acerca da subjetividade obstada - que, desde 2005, vem sendo desenvolvida no Departamento de Psicologia (DPSIC) e no Laboratório de Pesquisa e Intervenção Psicossocial (LAPIP) da Universidade Federal de São João Del-Rei (UFSJ).

3 Estabeleceu-se a parceria com representantes das comunidades das cidades pesquisadas para viabilização de uma exibição do Filme Narrativas de artesãos - o tal do filme, em local público, aberta a toda a comunidade com entrada franca, em cada uma das cidades pesquisadas. Ressalta-se ainda, que uma cópia do Filme em DVD foi disponibilizada a cada artesão, às prefeituras, escolas e locais de interesse público e cultural da Região, em forma de doação e com restrições claras sobre seu caráter público, sem fins lucrativos.

${ }^{4}$ No texto intitulado Experiência e Pobreza, Benjamin (1933/1985) propõe um novo conceito de barbárie, que surge da pobreza da experiência de toda a humanidade e se mantém por meio da obstrução dos sentidos humanos. Entendimento que também perpassa a explanação de Adorno (1968/1995) sobre as marcas no corpo e no espírito por se viver aquém das condições materiais já alcançadas. 